\title{
Application of SVM Algorithm for Frictional Pressure Loss Calculation of Three Phase Flow in Inclined Annuli
}

\author{
Arya Shahdi ${ }^{1}$ and Milad Arabloo ${ }^{*}$ \\ ${ }^{1}$ Department of Petroleum Engineering, Islamic Azad University, Science and Research Branch, Tehran, Iran \\ ${ }^{2}$ Department of Petroleum Engineering, Petroleum University of Technology, Ahwaz, Iran
}

\begin{abstract}
In Underbalanced Drilling (UBD) operation, the presence of three phases including, drilling fluid, air and cuttings, makes the estimation of equivalent circulation density more difficult. This study presents a novel computer-based model namely Lease Square Support Vector Machine (LS-SVM), for frictional loss calculation of two-phase gas based drilling fluids with the presence of cuttings as the third phase in inclined section of wellbore. This model is based on extensive experimental data collected from published literature. This model is account for in situ flow rate of each phase, Rate of Penetration (ROP), pipe rotation, and hole inclination. The results show that the proposed model is predicting frictional pressure losses in acceptable agreement with experimental data with very high correlation coefficient $(>0.99)$ and small average relative error. Moreover, a trend analysis was carried out to check the validity of the developed model. Results of the present study show that implementation of this developed model can be incorporated in drilling simulators for accurate estimation of frictional pressure loss of three phase flow.
\end{abstract}

Keywords: Pressure loss; Three phase flow; LS-SVM; Sensitivity analysis

\section{Introduction}

Drilling operations and techniques are effectively improving in order to get into better results with avoidance of any unfortunate incidents. Extractable hydrocarbon is highly dependent on drilling operations and measurements. Every action should be precisely taken in total steps from drilling to production. Drilling fluids play pivotal role in drilling operations while could be highly deleterious to productive formations. Unavoidably, the phenomenon of invasion occurs during Over Balanced Drilling (OBD) which causes lots of damages to the formations [1]. These damages could result in less possible recoverable oil friction with the consequences of losing natural energy source and money. A relatively new drilling method resolved many damaging related problems which is called UBD [2]. It applies mostly in reservoirs with depleted pressure in order to prevent lost circulation, pipe sticking, formation damages, etc [3-5].

In UBD method, the formation pressure is higher than drilling fluid pressure. Choosing the best drilling fluid is crucially significant. Aerated fluids are widely acceptable to the procedure and broadly used as light fluid in UBD [6-8]. Cleaning capability is one the most important criteria in drilling fluid efficacy [9-11]. Thus, a comprehensive understanding of whole cleaning related functions is required. Aerated drilling fluid, is used in UBD, has two phases (gas and liquid) and consequently includes two flow patterns in the annulus. In aerated drilling fluids, each phase is supposed to do a specific job, cuttings should be transported by the liquid phase while pressure has to be set by the gas phase $[12,13]$. Detecting the minimum required flow rate of each phase, in two-phase drilling fluid, is important in optimizing the cutting transportation and hole cleaning efficiency [14,15]. Pressure distribution and well inclination are two factors should be regarded as substantial elements in modeling any flow pattern in annulus especially in under balanced drilling. Accurate equivalent circulation density approximation is highly important which is affected by the existence of two phases and pressure drop in aerated drilling fluid [16]. Pressure status should be taken into consideration in the annulus. Pressure drop also needs to be considered as one of the other significant factor in UBD. By discoursing the hydrodynamic behavior and the carrying capability of gasified drilling fluids accompanied with inclined annular geometries, the need of an ever increasing importance of a better understanding of cuttings transport procedure will be satisfied. Although previous researchers on the hydrodynamic behavior of aerated drilling fluids are extensive [1722], an investigation on the cutting transport modeling of three phase flow has not received enough attention. To this end, this study presents a novel computer-based namely Lease Square Support Vector Machine (LS-SVM), for frictional loss calculation of two-phase gas based drilling fluids with the presence of cuttings as the third phase in inclined section of wellbores. This model is based on extensive data collected from published literature. This intelligent model is account for in situ flow rate of each phase, Rate of Penetration (ROP), pipe rotation, and whole inclination.

\section{Methodology}

\section{Background of the model}

The least square version of the SVM (LS-SVM) which widely used in complex system studies for modeling, regression or parameter prediction was described in Suykens and Vandewalle (1999). The theory of LS-SVM is well described by previous researches [23-26].

Considering the problem of approximating a given dataset $\left\{\left(\mathrm{x}_{1}, \mathrm{y}_{1}\right),\left(\mathrm{x}_{2}, \mathrm{y}_{2}\right), \ldots\left(\mathrm{x}_{\mathrm{N}}, \mathrm{y}_{\mathrm{N}}\right)\right\}$ with a nonlinear function:

$$
f(\mathrm{x})=\langle\mathrm{w}, \phi(\mathrm{x})\rangle+\mathrm{b}
$$

where $\langle.,$.$\rangle represent dot product; \Phi(x)$ represents the nonlinear function that maps $x$ into $\mathrm{n}$-dimensional feature space and performs

*Corresponding author: Milad Arabloo, Department of Petroleum Engineering Petroleum University of Technology, Ahwaz, Iran, Tel: 982147911; E-mail: milad.arabloo@gmail.com

Received May 26, 2014; Accepted July 16, 2014; Published July 23, 2014

Citation: Shahdi A, Arabloo M (2014) Application of SVM Algorithm for Frictional Pressure Loss Calculation of Three Phase Flow in Inclined Annuli. J Pet Environ Biotechnol 5: 179. doi:10.4172/2157-7463.1000179

Copyright: $\odot 2014$ Shahdi A, et al. This is an open-access article distributed under the terms of the Creative Commons Attribution License, which permits unrestricted use, distribution, and reproduction in any medium, provided the original author and source are credited. 


\begin{tabular}{|c|c|c|c|}
\hline Parameter & Minimum & Maximum & Mean \\
\hline$R O P$ & 80 & 120 & 98.52 \\
\hline$R P M$ & 0 & 120 & 77.04 \\
\hline$\Theta$ & 0 & 75 & 32.18 \\
\hline$V_{s l}$ & 2.0 & 5.0 & 2.69 \\
\hline$V_{s g}$ & 0.2 & 33.86 & 13.55 \\
\hline$D p$ & 0.05 & 0.70 & 0.33 \\
\hline
\end{tabular}

Table 1: Descriptive statistics of the applied data sets.

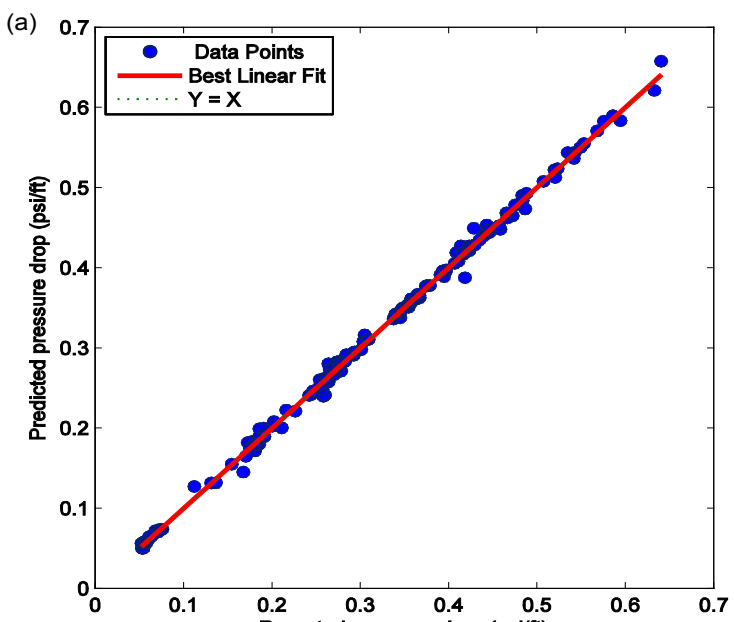

(b)
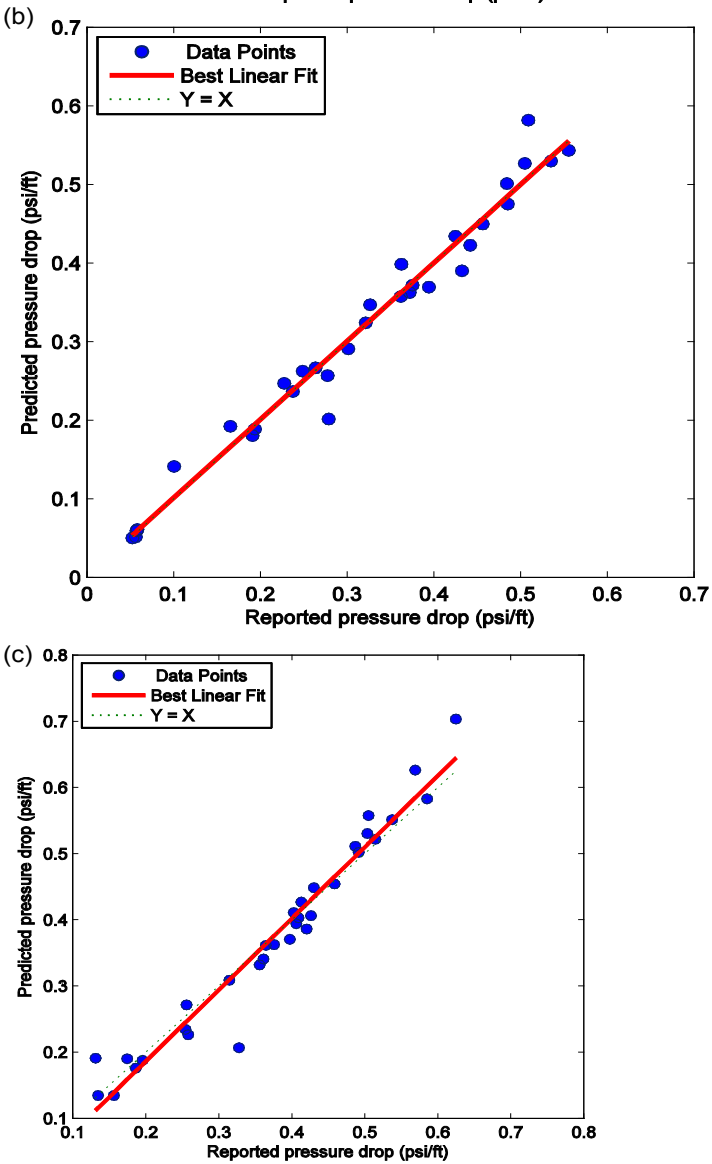

Figure 1: Comparison between predicted and reported data pressure drop for (a): train set; (b): validation set; (c): test set. linear regression; $\boldsymbol{w}$ and $b$ are weight vector and bias terms. In LSSVM for function estimation, the optimization problem is formulated as [24]:

$$
\begin{aligned}
& \min _{w, b, e} \mathrm{~J}(\mathrm{w}, \mathrm{e})=\frac{1}{2}\|w\|^{2}+\frac{1}{2} \gamma \sum_{k=1}^{N} e_{k}^{2} \\
& \text { s.t. } y_{k}=\left\langle w, \phi\left(\mathrm{x}_{\mathrm{k}}\right)\right\rangle+b+e_{k} \quad k=1, \ldots, N
\end{aligned}
$$

Where $e_{k} \in R$ are error variables; $\gamma \geq 0$ is a regularization constant. The Lagrangian is given by [24]:

$$
L_{L S-S V M}=\frac{1}{2}\|w\|^{2}+\frac{1}{2} \gamma \sum_{k=1}^{N} e_{k}^{2}-\sum_{k=1}^{N} \alpha_{k}\left\{\left\langle w, \phi\left(\mathrm{x}_{\mathrm{k}}\right)\right\rangle+\mathrm{b}+\mathrm{e}_{\mathrm{k}}-y_{k}\right\}
$$

With Lagrange multipliers $\alpha_{k} \in R$. The condition for optimally are given by [24]:

$$
\left\{\begin{array}{c}
\frac{\partial L_{L S-S V M}}{\partial w}=0 \rightarrow w=\sum_{k=1}^{N} \alpha_{k} \phi\left(\mathrm{x}_{\mathrm{k}}\right) \\
\frac{\partial L_{L S-S V M}}{\partial b}=0 \rightarrow \sum_{k=1}^{N} \alpha_{k}=0 \\
\frac{\partial L_{L S-S V M}}{\partial e_{k}}=0 \rightarrow \alpha_{k}=\gamma e_{k} \\
\frac{\partial L_{L S-S V M}}{\partial \alpha_{k}}=0 \rightarrow\left\langle w, \phi\left(\mathrm{x}_{\mathrm{k}}\right)\right\rangle+b+e_{k}-y_{k}=0
\end{array}\right.
$$

By defining $Y=\left[\mathrm{y}_{1} ; \ldots ; \mathrm{y}_{\mathrm{N}}\right], 1_{\mathrm{v}}=[1 ; \ldots ; 1], \alpha=\left[\alpha_{1} ; \ldots ; \alpha_{\mathrm{N}}\right]$ and eliminating $w$ and $e$, following linear equations are obtained [24]:

$$
\left[\begin{array}{ccc}
0 & 1_{N}^{T} \\
1_{N} & \Omega+\gamma^{-1} & I_{N}
\end{array}\right]\left[\begin{array}{l}
b \\
\alpha
\end{array}\right]=\left[\begin{array}{l}
0 \\
Y
\end{array}\right]
$$

Where $I_{N}$ is an $N \times N$ identity matrix, and $\Omega \in R^{N \times N}$ is the kernel matrix defined by

$$
\Omega_{k l}=\Phi\left(\mathrm{x}_{\mathrm{k}}\right) \Phi\left(\mathrm{x}_{1}\right)=\mathrm{K}\left(\mathrm{x}_{\mathrm{k}}, \mathrm{x}_{1}\right), \mathrm{k}, \mathrm{l}=1, \ldots \mathrm{N}
$$

As mentioned earlier, has a tuning parameter $\gamma$. From the other point, as the LS-SVM is a kernel based method, parameters of kernel function should be considered. For LS-SVM, there are many kernel function including linear, polynomial, Radial Basis Function (RBF), etc $[23,24]$. However, most widely used kernel function is RBF (Eq. (26)) $[25,27,28]$.

$$
K\left(\mathrm{x}_{\mathrm{k}}, \mathrm{x}_{1}\right)=\exp \left(-\left\|x_{k}-x_{l}\right\|^{2} / \sigma^{2}\right)
$$

Where, $\sigma^{2}$ is the squared variance of the Gaussian function. In the case of RBF kernel, we have another tuning parameter. As the result, the LS-SVM model with the RBF kernel function has two tuning parameters which should be obtained by minimization of the deviation of the LS-SVM model from experimental values $[29,30]$.

\section{Design of the model}

To develop model for accurate prediction of pressure drop, Rate of Penetration (ROP), Pipe Rotation Speed (RPM), hole inclination $\Theta$ ), and in situ flow rate of each as flows:

$$
D p=f\left(\mathrm{ROP}, \mathrm{RPM}, \theta, \mathrm{v}_{\mathrm{sl}}, \mathrm{v}_{\mathrm{sg}}\right)
$$

Where, $D p$ is pressure drop , psi/ft. To develop new model, a data bank from literature [31] was collected. A complete statistical description of the applied data bank [31] is given in Table 1.

\section{Results and Discussion}

To find the optimum values of the model's parameters including $\gamma$ and $\sigma^{2}$, Coupled Simulating Annealing [32] technique has been employed. The optimized values of these parameters are as follows: 


$$
\begin{aligned}
& \gamma=1.0549 \mathrm{E}+04 \\
& \sigma^{2}=6.0015
\end{aligned}
$$

Cross plots of the proposed LSSVM model estimations versus the corresponding target values for all three phases of training, validation, and test sets are shown in Figure 1. A tight cloud of points about $45^{\circ}$ line for training, validation and testing data sets indicate the robustness of the proposed models. In addition, for representing a better visual comparison, relative deviations of estimated values are plotted versus the target (reported) data in Figure 2 for all data. As illustrated, predictions are in a satisfactory agreement with the reported data Table 2.

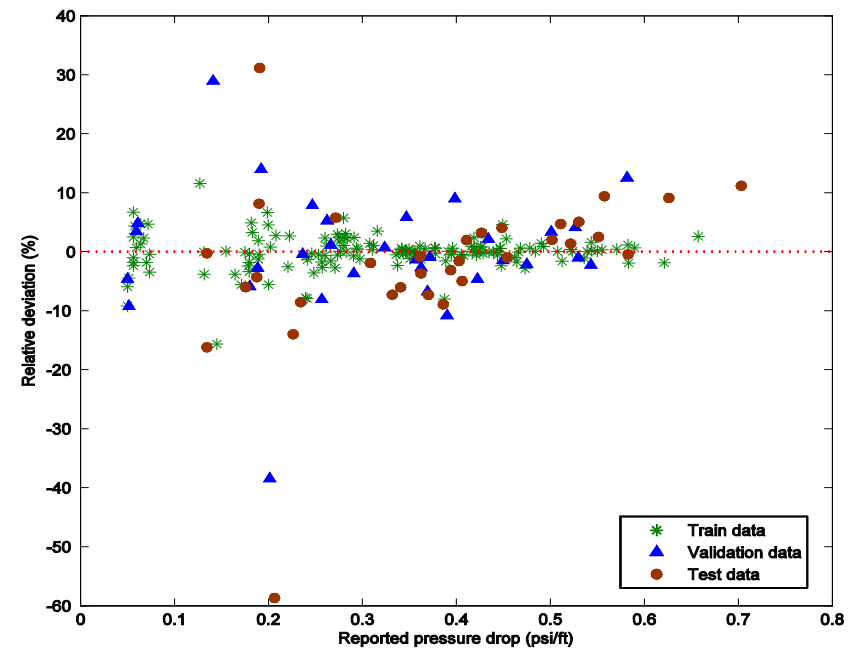

Figure 2: Relative deviations of predicted pressure drops versus target data.

\begin{tabular}{|l|c|}
\hline Parameter \\
\hline Training set \\
\hline $\mathrm{R}^{2}$ & \\
\hline Average relative deviation, \% & 0.9979 \\
\hline Average absolute relative deviation, \% & -0.092 \\
\hline Root mean square error & 1.867 \\
\hline $\mathrm{N}$ & 0.007 \\
\hline Validation set & 151 \\
\hline $\mathrm{R}^{2}$ & \\
\hline Average relative deviation, \% & 0.9713 \\
\hline Average absolute relative deviation, \% & -0.138 \\
\hline Root mean square error & 6.573 \\
\hline $\mathrm{N}$ & 0.025 \\
\hline Test set & 32 \\
\hline $\mathrm{R}^{2}$ & \\
\hline Average relative deviation, \% & 0.9514 \\
\hline Average absolute relative deviation, \% & -1.684 \\
\hline Root mean square error & 7.721 \\
\hline $\mathrm{N}$ & 0.034 \\
\hline Total & 33 \\
\hline $\mathrm{R}^{2}$ & \\
\hline Average relative deviation, \% & 216 \\
\hline Average absolute relative deviation, \% & \\
\hline Root mean square error & -0.342 \\
\hline $\mathrm{N}$ & 3.459 \\
\hline & 0.018 \\
\hline
\end{tabular}

Table 2: The statistical parameters of the developed model.

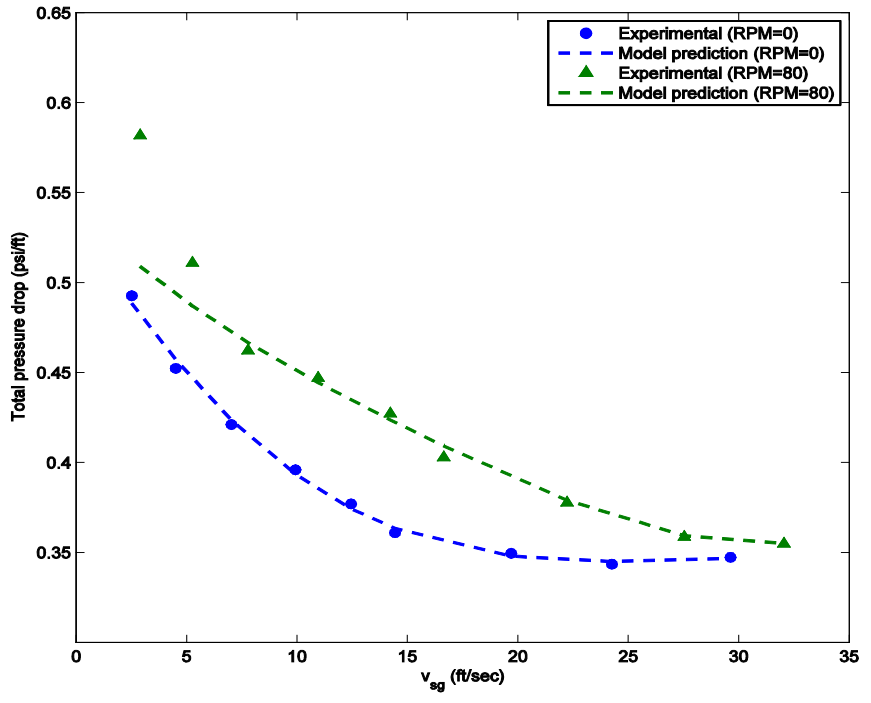

Figure 3:Measured and predicted pressure drop versus gas superficial velocity $\left(\Theta=12.5, \mathrm{ROP}=80 \mathrm{ft} / \mathrm{hr}, V_{s i}=3.0 \mathrm{ft} / \mathrm{sec}\right)$.

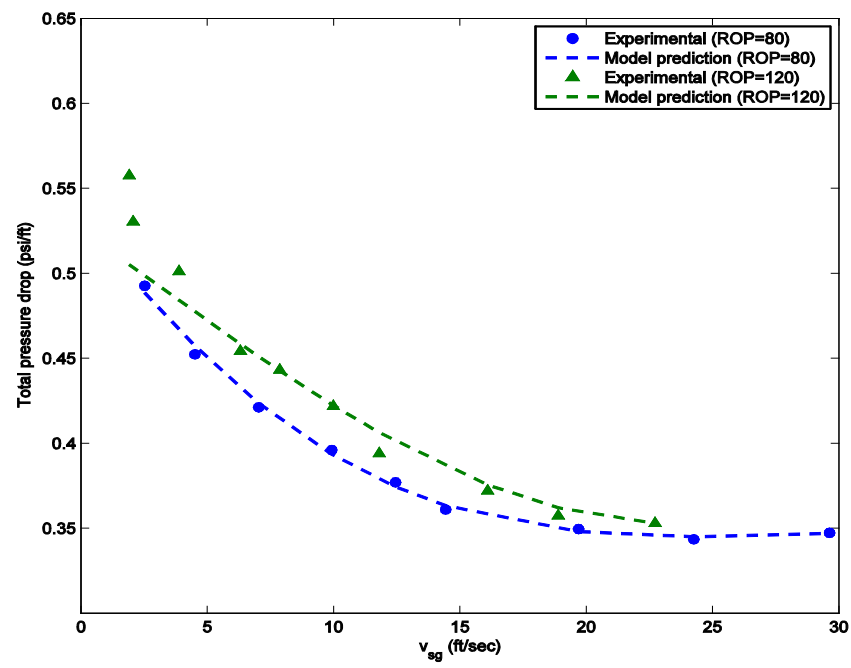

Figure 4:Measured and predicted pressure drop versus gas superficial velocity $\left(\Theta=12.5, \mathrm{RPM}=0 \mathrm{ft} / \mathrm{hr}, V_{s i}=3.0 \mathrm{ft} / \mathrm{sec}\right)$.

A trend analysis was also carried out in order to examine whether the developed model is physically accurate or not. To this end, the model responses to various input parameters. Figure 3 illustrates the trend of changes of pressure drop as a function of superficial gas velocity for typical values of RPM. As shown in this Figure 3, the model has captured the trend of increasing pressure drop with increasing drill pipe rotation. Rate of penetration causes an increase in total pressure drop at low gas flow rates (Figure 4). As expected, the developed model also captures this trend. Moreover, Figure 5 shows the effect of liquid velocity on pressure loss for three phase flow in nearly vertical annuli. The model response is entirely consistent with increasing trend of pressure loss versus liquid superficial velocity.

\section{Conclusions}

The application of a novel machine learning method namely 
Citation: Shahdi A, Arabloo M (2014) Application of SVM Algorithm for Frictional Pressure Loss Calculation of Three Phase Flow in Inclined Annuli. J Pet Environ Biotechnol 5: 179. doi:10.4172/2157-7463.1000179

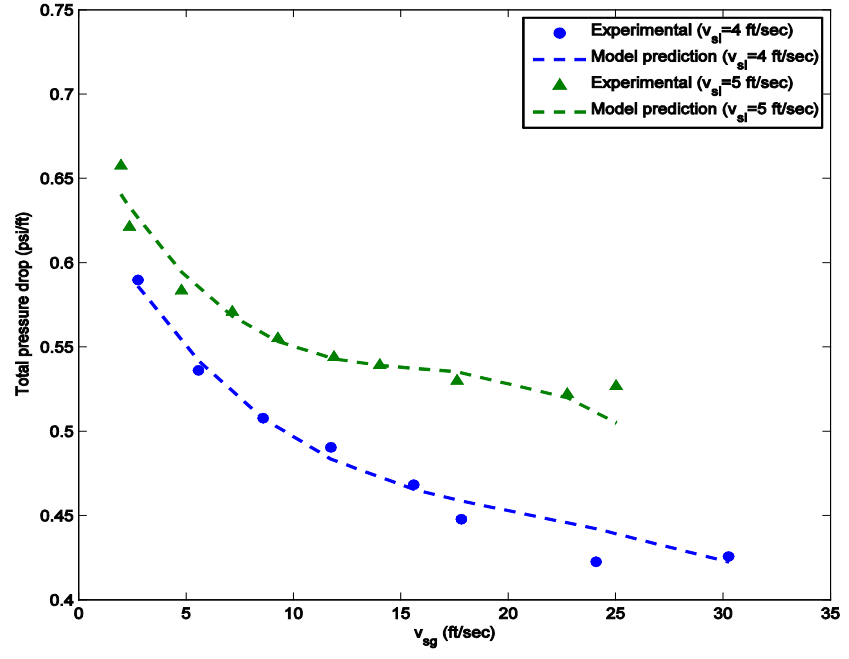

Figure 5: Measured and predicted pressure drop versus gas superficial velocity $(\theta=12.5, \mathrm{RPM}=80 \mathrm{ft} / \mathrm{hr}, \mathrm{ROP}=80(\mathrm{ft} / \mathrm{hr}))$.

Least Square Support Vector Machine (LS-SVM) model for improved prediction of frictional loss of two-phase gas based drilling fluids with the presence of cuttings was studied in this work. Various influencing parameters including in situ flow rate of liquid and gas phases, Rate of Penetration (ROP), pipe rotation, and hole inclination were considered as the correlating parameters. The model was developed and tested using a total set of 216 experimental datasets covering a wide range of variables. The results show that the developed model provides predictions in acceptable agreement with target data. Also it was shown that the model is capable of simulating the actual physical trend of the total pressure loss versus changing input parameters.

\section{References}

1. Suri A, Sharma MM (2004) Strategies for Sizing Particles in Drilling and Completion Fluid. Soc Petrol Eng J 9: 13-23.

2. Bingham M (1969) What is Balanced Pressure Drilling? Fall Meeting of the Society of Petroleum Engineers of AIME, Denver, Colorado, USA.

3. Guo B, Ghalambor A (2002) An Innovation in Designing Underbalanced Drilling Flow Rates: A Gas-Liquid Rate Window (GLRW) Approach. IADC/SPE Asia Pacific Drilling Technology, 8-11 September, Jakarta, Indonesia.

4. Shayegi S, Lovorn R (2007) Comparison of reservoir knowledge, drilling benefits and economic advantages of UB, MP. Managed Pressure Drilling 6065.

5. Salehi S, Nygaard R (2011) Evaluation of New Drilling Approach for Widening Operational Window: Implications for Wellbore Strengthening. SPE Production and Operations Symposium, 27-29 March, Oklahoma City, Oklahoma, USA.

6. Arabloo M, Shahri MP, Zamani M (2012) Characterization of Colloidal Gas Aphron-Fluids Produced from a New Plant-Based Surfactant. J Disper Sci Technol 34: 669-678.

7. Ziaee H, Arabloo M, Ghazanfari MH, Rashtchian D (2014) Herschel-Bulkley rheological parameters of lightweight colloidal gas aphron (CGA) based fluids. Chem Eng Res Des.

8. Nareh'ei MA, Shahri MP, Zamani M (2012) Rheological and Filtration Loss Characteristics of Colloidal Gas Aphron Based Drilling Fluids. Journal of the Japan Petroleum Institute 55: 182-190.

9. Ozbayoglu ME, Osgouei RE, Ozbayoglu A, Yuksel E (2010) Estimation of VeryDifficult-to-Identify Data for Hole Cleaning, Cuttings Transport and Pressure Drop Estimation in Directional and Horizontal Drilling. IADC/SPE Asia Pacific Drilling Technology Conference and Exhibition, 1-3 November, Ho Chi Minh City, Vietnam.
10. Rooki R, Ardejani FD, Moradzadeh A (2014) Hole Cleaning Prediction in Foam Drilling Using Artificial Neural Network and Multiple Linear Regression. Geomaterials 4: 47-53.

11. Arabloo M, Shahri MP (2014) Experimental studies on stability and viscoplastic modeling of colloidal gas aphron (CGA) based drilling fluids. J Petrol Sci Eng 113: 8-22.

12. Totten PL, King BL, Griffith JE (1998) Method of performing well drilling operations with a foamable drilling fluid. US5851960 A

13. Perez-Tellez C (2003) Improved Bottomhole Pressure Control for Underbalanced Drilling Operations. The Department of Petroleum Engineering, Louisiana State University USA.

14. Vieira P, Miska S, Reed T, Kuru E (2002) Minimum Air and Water Flow Rates Required for Effective Cuttings Transport in High Angle and Horizontal Wells. IADC/SPE Drilling Conference, 26-28 February, Dallas, Texas USA.

15. Pedersen T, Godhavn JM (2013) Model Predictive Control of Flow and Pressure in Underbalanced Drilling. 10th IFAC International Symposium on Dynamics and Control of Process Systems, The International Federation of Automatic Control December 18-20, 2013. Mumbai, India.

16. Osgouei RE, Yoong WLS, Ozbayoglu EM (2013) Calculations of Equivalent Circulating Density in Underbalanced Drilling Operations. International Petroleum Technology Conference, 26-28 March, Beijing, China.

17. Caetano EF, Shoham O, Brill JP (1992) Upward Vertical Two-Phase Flow Through an Annulus-Part I: Single-Phase Friction Factor, Taylor Bubble Rise Velocity, and Flow Pattern Prediction. J Energy Resour Technol 114: 1-13.

18. Sadatomi M, Sato Y (1982) Two-phase flow in vertical noncircular channels. Int J Multiphas Flow 8: 641-655.

19. Beggs DH, Brill JP (1973) A Study of Two-Phase Flow in Inclined Pipes. J Petro Technol 25: 607-617

20. Hasan AR, Kabir CS, Rahman R (1988) Predicting Liquid Gradient in a Pumping-Well Annulus. Soc Petrol Eng J 3: 113-120.

21. Ozbayoglu EM, Ozbayoglu MA (2009) Estimating Flow Patterns and Frictional Pressure Losses of Two-Phase Fluids in Horizontal Wellbores Using Artificial Neural Networks. Pet Sci Technol 27: 135-149.

22. Taitel Y, Dukler AE (1976) A model for predicting flow regime transitions in horizontal and near horizontal gas-liquid flow. AIChE J 22: 47-55.

23. Suykens JK, Van Gestel T, Vandewalle J, De Moor B (2003) A support vector machine formulation to PCA analysis and its kernel version. IEEE Trans Neura Netw 14: 447-450.

24. Suykens J (2002) Least Squares Support Vector Machines. NATO-ASI Learning Theory and Practice Leuven.

25. Shokrollahi A, Arabloo M, Gharagheizi F, Mohammadi AH (2013) Intelligent model for prediction of $\mathrm{CO} 2$ - Reservoir oil minimum miscibility pressure. Fue 112: 375-384.

26. Farasat A, Shokrollahi A, Arabloo M, Gharagheizi F, Mohammadi AH (2013) Toward an intelligent approach for determination of saturation pressure of crude oil. Fuel Process Technol 115: 201-214.

27. Fayazi A, Arabloo M, Shokrollahi A, Zargari MH, Ghazanfari MH (2014) Stateof-the-Art Least Square Support Vector Machine Application for Accurate Determination of Natural Gas Viscosity. Ind Eng Chem Res 53: 945-958.

28. Rafiee-Taghanaki S, Arabloo M, Chamkalani A, Amani M, Zargari MH, et al. (2013) Implementation of SVM framework to estimate PVT properties of reservoir oil. Fluid Phase Equilibr 346: 25-32.

29. Nejatian I, Kanani M, Arabloo M, Bahadori A, Zendehboudi S (2014) Prediction of natural gas flow through chokes using support vector machine algorithm. Journal of Natural Gas Science and Engineering 18: 155-163.

30. Fayazi A, Arabloo M, Mohammadi AH (2014) Efficient estimation of natural gas compressibility factor using a rigorous method. Journal of Natural Gas Science and Engineering 16: 8-17.

31. Osgouei RE, Eren T, Ozbayoglu ME, Ozbayoglu A (2013) Three Phase Flow Characteristics in Inclined Eccentric Annuli. SPE/IADC Middle East Drilling Technology Conference \& Exhibition, 7-9 October, Dubai, UAE.

32. Xavier-de-Souza S, Suykens JA, Vandewalle J, Bolle D (2010) Coupled simulated annealing. IEEE Trans Syst Man Cybern B Cybern 40: 320-335. 